\title{
THE FACTORS THAT AFFECT THE EFFECTIVENESS OF TRAINING: A STUDY AT SILTERRA MALAYSIA SDN. BHD., A SEMICONDUCTOR COMPANY IN MALAYSIA
}

\author{
ABDULLAH LIN \\ GUNALAN A/L NADARAJAH \\ Othman Yeop Abdullah Graduate School of Business \\ Universiti Utara Malaysia \\ MOHMAD YAZAM SHARIF \\ ABUL BASHAR BHUIYAN \\ School of Business Management \\ Universiti Utara Malaysia \\ MD. AMINUL ISLAM \\ School of Business Innovation and Technopreneurship \\ Universiti Malaysia Perlis
}

\begin{abstract}
The purpose of this study is to identify the factors that can affect the effectiveness of the Yield Management training program at a semiconductor company. The research framework for this study was designed based on the Kirkpatrick model and questionnaires were distributed to the technical staff at Silterra. The study found that factors such as participants, trainer, training materials and organization could affect the effectiveness of the training while other factors such as the training program itself, working environment and technology were immaterial. The results also indicated that participants, trainer, training material and the organization had a positive relationship with the effectiveness of training at the different levels of the Kirkpatrick's evaluation model.
\end{abstract}

Keywords: Training effectiveness, technical training, Yield Management training program, Kirkpatrick's Training Model, Semiconductor industry.

\section{Introduction}

The Malaysian government was proud to announce its success in acquiring a state-of-the-art technology used in silicon wafer 
fabrication that requires very stringent technical specifications and a series of complex processes, to operate. In view of this, the government invested billions of ringgit to bring this technology to the country. The technology was then installed at Silterra Malaysia Sdn Bhd, a semiconductor company involved in wafer manufacturing. Thus, this study has a significant bearing on human resources practitioners at Silterra who are responsible for training and recruiting the appropriate employees to operate this new technology for the semiconductor company. The findings of this study reveal the attributes required for training programs to be effective. This would also provide answers to some of the questions in relation to employee training and development, an important focus in the nation's workforce development agenda. While many factors were known to affect the success of learning, this study attempts to focus on the aspect of the 'effectiveness' of the training as the dependent variable for the study. The study is also important to training and development practitioners as it provides relevant information pertaining to achieving effectiveness in their training programs. By understanding the factors that are directly impacting the effectiveness of training, trainers would be able to eradicate some of the assumptions on the learning ability of new employees. Thus, they would also be able to focus more attention on trainees who are having difficulties in learning.

\section{Problem Statement}

Most organizations fail to understand the factors that may impact the effectiveness of training. As such, many organizations have failed to treat the evaluation of training as a priority (Kirkpatrick, 2005; Mondy, 2008; Noe, 2008). At best, the evaluation of training has been a perfunctory task with little analysis and usefulness (Goldstein, 1986; Hashim 2001; Mondy 2008; Giangreco, Carugati \& Sebastiano, 2010). Yet, evaluating the effectiveness of such costly efforts is paramount to the success of any training program (Giangreco et al., 2010). In order to see the effectiveness of training programs, we have to seriously consider the influencing factors by evaluating them using suitable training evaluation models. This is to ensure the money invested for training is well worth and brings results in achieving the company's objectives. In addition, evaluation of the effectiveness of training is given lesser priority (Kirkpatrick, 2005, Mondy, 2008) in the instructional process; a contention, supported by the small number 
of articles in the literature that deals with the subject. In the current economic environment and in light of the establishment of the HR Development Council (HRDC), training personnel are expected to face difficult economic decisions about the viability and value of the programs they offer. They need concrete evidence that demonstrate the quality of their programs, in order to make effective decisions and influence the management of the company (Noe, 2008). Thus, for this to happen the meaning of evaluation must be clarified and its purpose(s) must be clearly identified (Giangreco et al., 2010).

\section{Objectives}

The first objective of this study is to determine the factors that affect the effectiveness of training for the Yield Management program at Silterra Malaysia Sdn. Bhd. The second objective of this study is to investigate the relationship between the factors and training effectiveness.

\section{Background}

\section{Training Programs at Silterra Malaysia Sdn. Bhd.}

Silterra Malaysia has divided the training programs into three main categories; Core Training, Elective Training and External Training. The Core Training programs are compulsory for all employees and the number of programs in Core Training differs depending on the employee's job category. The Yield Management program (i.e. Core Training) wasselected for this study. To identify whether the objectives of the training were achieved, the Kirkpatrick's training evaluation model was used. Many training evaluation models are available to measure the effectiveness of the program. However, it is most important to look at a model which the organization focuses its evaluation on. In view of the above, the four levels of Kirkpatrick Training Evaluation Model were used as the basis for this study. Based on the literature researched, "there is no right answer to what is the 'best' model to use"(Billington et al., 2009; Cannon-Bowers et al., 1995; Edulbehram J. \& Rascher, 1996; Giangreco et al, 2010; Kirkpatrick,1994,1996, 2005; \& Mathieu et al., 1992). The four levels of Kirkpatrick are reaction, learning, behavior and result. 


\section{Yield Management Program}

The Yield Management program wasselected to be used for the actual study. The Yield Management program is a technical training program designed for all technical staff at Silterra Malaysia Sdn. Bhd. This program is made compulsory for all technicians and engineers, and is classified as a Core Program for them. These categories of employees must complete this training program during their probation period, failing which their probation period would be extended till they successfully complete the program. The objective of the Yield Management program is to provide participants with the understanding of yield or quality, calculating the yield, the impact of poor yield to the company and customers, and actions to be taken before and after to ensure the yield of the product meets customers' expectations. The program is based on a workshop that involves classroom discussions and exercises. There are a few exercises in this training program which demonstrate to the participants how to calculate yield, manufacturing costs and wastages. To further strengthen their understanding, the program requires employees to practically improve the final product. Through this program, the participants will also be taught the importance of being alert in their work since every step of their work to produce the semiconductor wafer will have an impact on the product yield, productivity, operation costs and wastages. Thus, their commitment to the work is crucial. The duration of this program is approximately six hours. However, the program can be extended to seven or eight hours, depending on the number of participants and their ability to successfully complete the exercises.

\section{Factors on Training Effectiveness}

An important aspect which the management of the company had failed to consider was the factors that contribute to the effectiveness of the training conducted. Some of these factors that could affect the effectiveness of training, as mentioned earlier, are the participants, trainers, training materials, training programs, the company, the working environment and technology. It should be recognized that participants attending the program must, firstly have the motivation to attend the training program or else they may not learn anything from the training (Al-Eisa et al., 2009; Asplund \& Salverda, 2004; Billington et al., 2009; Cannon-Bowers et al., 1995; Edulbehram J., \& Rascher, 1996; Kirkpatrick, 1977; Mathieu et al., 1992). It was also suggested that a good evaluation system is a collaborative process that 
includes evaluating trainers (Lingham \& Rezaria, 2006, Savolainen, 2000). Here, there is no doubt that trainers play an important role in making the training program lively by regularly obtaining feedback from the participants to see if they understood the subject that is being taught (Tai, 2006).It is also important for the trainer to get to know more about the participants at the beginning stage of the training program to ensure that it is effective (Kirkpatrick, 1977; 2005). Boyce (1996) said that adults were quickly frustrated and developed poor attitudes towards training if they felt their time spent was wasted on training materials that were not useful. Barkala \& Gutierrez (2000) also stated the importance of the content in the program design and to ensure that it could be used at present, as well as remain relevant in the future. Barkala and Gutierrez (2000) stressed that it is important for the training program to be relevant to the employee's job. Though the success of the training program primarily relies on the program design itself, maximum training effectiveness could not be achieved without subjective factors such as organizational support (Tai, 2006). Noe (2008) in particular argued that knowledge interaction between senior managers and employees had a significant impact on the employees' worksite application rate. In other words, though the trainees were properly trained, they could not fully apply their training at the workplace if there was not enough support or the surroundings were not conducive for such applications. Ellis (1965) stated that the work environment had an impact on training effectiveness. The working environment in this context includes the support from the management and peers, and the nature of work (Arsaythamby \& Kiew, 2012; Zafir \& Fazilah, 2011; Noe A. R., 2008; McGettingan \& O'Neill, 2009; Tai, 2006; Tsai \& Tai, 2003). William et al. (2003) stated that it is very important for the training administrator to provide suitable training equipment to support outdoor training activities. On the other hand, (Sanlier \& Karakus, 2010) found that well-arranged furniture such as racks, tables and chairs will foster learning activities and attract employees to attend the training program (Harvey et al., 2001).

\section{Methodology}

\section{Research Framework}

The main purpose of this study was to identify the factors that affect the training effectiveness at Silterra Malaysia Sdn. Bhd., the semiconductor wafer (wafer fab) company. Figure 3.1 is the theoretical framework 
that indicates the relationship between two types of variables which are the independent and the dependent variables. The independent variables consist of factors that affect the effectiveness of training. The dependent variables are the effectiveness of training derived from the reaction of the participants, knowledge and skill acquisition, and lastly, the return of investment (ROI). The analysis for this study was based on the quantitative data collected. The effectiveness levels of the trained employees were analysed using data gathered from the technical staff of Silterra Malaysia Sdn. Bhd.

\begin{tabular}{|l|l|l|}
\hline \multicolumn{2}{|l|}{ Independent Variables } & \\
1. Participant & Dependent Variables \\
2. Trainer & Training Effectiveness \\
3. Training Material & a. Reaction \\
4. Training Program (Yield Management) & b. Learning \\
5. Organization & c. Behaviour \\
6. Working Environment & d. Result \\
7. Technologv & \\
\cline { 2 - 2 } &
\end{tabular}

Figure 3.1 The research framework.

\section{Research Instrument}

The research population was sampled from the employees of the wafer fab company, Silterra Malaysia Sdn Bhd. Data were collected through the distribution of questionnaires. The questionnaire comprised four main components -information about the respondent, technical training program (i.e. Yield Management), factors affecting training, and effectiveness of training. The research model used served as a basis for the construction of the questionnaires. The questionnaire method used also attempted to avoid biasness of the researcher (Sadri \& Snyder, 1995; Spatz \& Kardas, 2008). It was designed to provide a feeling of anonymity to the respondents who then would be able to provide genuine responses, place less pressure for immediate responses and enable researchers to measure perceptions more accurately (Emory, 1985; Smith \& Piper, 1990). All variables in this study were measured using the Likert 5 -point rating scale. Out of the total of 90 questions that were developed, 56 questions represented the independent variables and 34 questions represented the dependent variables. The statistical software, SPSS version 16, was used to analyse the data. 


\section{The Research Approach}

The survey method was used by distributing questionnaires to the respondents that included technicians, engineers and technical managers. A total of 294 sets of questionnaires were distributed through face-to-face meetings conducted by the HRD team at Silterra. Out of these, 201 sets of questionnaires were returned with seven sets rejected due to incomplete answers. Discounting the number rejected, a total of 194 sets of questionnaires were usable, resulting in a 66 per cent return rate.

\section{Results}

Statistical procedures were applied to ensure the validity and reliability of this survey-based measure for theoretical assessment. In terms of the survey's validity, a procedure called factor analysis allowed the researcher to ascertain if the number of items could be reduced to the number of concepts that were initially hypothesized. A reliability analysis was conducted on each of the seven dimensions of the independent variables, as well as four dimensions of the dependent variables. Table 4.1 shows the result of the reliability analysis.

Table 4.1

Reliability Analysis: Alpha Coefficients

\begin{tabular}{lrrrc}
\hline \multicolumn{1}{c}{ Factors } & $\begin{array}{r}\text { Total no } \\
\text { of items }\end{array}$ & $\begin{array}{c}\text { No of } \\
\text { items } \\
\text { dropped }\end{array}$ & $\begin{array}{r}\text { No of } \\
\text { items } \\
\text { used }\end{array}$ & $\begin{array}{c}\text { Cronbach } \\
\text { alpha }\end{array}$ \\
\hline Independent Variable & 10 & 0 & 10 & 0.96 \\
Participant & 9 & 3 & 6 & 0.92 \\
Trainer & 9 & 2 & 7 & 0.96 \\
Training Material & 9 & 4 & 5 & 0.93 \\
Training Program (Yield Management) & 6 & 3 & 3 & 0.94 \\
Company & 8 & 1 & 7 & 0.96 \\
Working Environment & 5 & 2 & 3 & 0.69 \\
Technology & & & & \\
Dependent Variable & 11 & 4 & 7 & 0.93 \\
Reaction & 7 & 0 & 7 & 0.92 \\
Learning & 10 & 4 & 6 & 0.93 \\
Behaviour & 6 & 0 & 6 & 0.83 \\
Result & & &
\end{tabular}


Regression analysis was used to find out the factors that affected training effectiveness. The hypotheses and the research questions were tested by means of multiple regressions. The mediating analyses were verified to be free from any violation of the assumptions of least squares procedures used in the multiple regression analyses. The rationale behind conducting the diagnostic procedures was to ensure whether the errors in prediction were the result of the absence of a relationship among the factors that affect training effectiveness. Table 4.2 shows the result of the regression analysis between reaction and the independent variables.

Table 4.2

Regression Analysis between reaction and the independent variables - Result of Multiple Regression Analysis

\begin{tabular}{|c|c|c|c|c|}
\hline \multicolumn{2}{|l|}{ Variables } & Beta & T-ratio & Sig. $t$ \\
\hline \multicolumn{2}{|l|}{ Participant } & .161 & 2.019 & $.045^{*}$ \\
\hline \multicolumn{2}{|l|}{ Trainer } & .008 & .107 & .915 \\
\hline \multicolumn{2}{|c|}{ Training Material } & .177 & 2.068 & $.040^{*}$ \\
\hline \multicolumn{2}{|c|}{ Yield Management Training Program } & .071 & .889 & .375 \\
\hline \multicolumn{2}{|l|}{ Company } & .076 & .961 & .338 \\
\hline \multicolumn{2}{|c|}{ Working Environment } & .055 & .704 & .482 \\
\hline \multicolumn{2}{|l|}{ Technology } & .039 & .535 & .593 \\
\hline R Square & .169 & & & \\
\hline $\mathrm{F}$ & 5.417 & & & \\
\hline Sig. F & .000 & & & \\
\hline Durbin-Watson & 1.366 & & & \\
\hline
\end{tabular}

Note: ${ }^{*} p<0.05$

Participants (sig $t=.045)$ and training material (sig $t=.040)$ have significant effects on reaction at the $5 \%$ significance level. On the other hand, trainer ( $\operatorname{sig} t=.915)$, training program ( $\operatorname{sig} t=.375)$, company (sig $\mathrm{t}=$. 338), working environment (sig $\mathrm{t}=.482$ ) and technology (sig $t=.593$ ) have no significant effect on reaction. The $R$ square is 16.9 percent. This means that the regression model used for this study could explain 16.9 percent variations on training effectiveness. This also meant that there are other factors associated to training effectiveness. The Durbin-Watson fell within the acceptable range (1.366). Therefore, there was no auto-correlation problem in the data. The F-value $(\mathrm{F}=5.417)$ was found to be significant at one percent 
significance level (sig $\mathrm{F}=0.000$ ). This indicates that the regression model used in this study was adequate or in other words, the model was fit.

\section{Discussions}

The results showed the participants and the training material had an effect on reaction; trainer had an effect on learning and lastly, the training material and company had an effect on results. Based on our findings, the participants and the training material had a significant relationship with reaction; trainer had a significant relationship with learning, and training materials and company had significant relationships with results. On the other hand, in this study, trainer, Yield Management training program, company, working environment and technology had no significant bearing on reaction; participant, training material, Yield Management training program, company, working environment and technology had no significant relationship with learning; training material, Yield Management training program, and technology had no significant relation to behavior and lastly participant, Yield Management training program, working environment and technology had no significant relationship with results. These 23 non-positively related dimensions did not mean that they were not important but only that in this scope of study it did not possess any significant relationships.

\section{Implications}

The result of this study will have direct implications to the academic study, as well as the manufacturing industry especially towards the senior management team in the semiconductor industry. In addition, it will also impact the Malaysian Government in terms of how they formulate policies and strategies pertaining to workforce development. There are a number of areas that the academia, senior management or training managers, and government need to work on for improvement.

\section{Theoretical Implication}

Basically, the Kirkpatrick theory underlines the level of evaluation and anticipated outcomes of each level of evaluation. Unfortunately, its process and methodology were not discussed and shared in 
detail. As such, the significance of the Kirkpatrick theory would not have surfaced if there had been no study on the actual evaluation process. Hence, by incorporating the evaluation process of the training program, measurements could be introduced to measure the effectiveness of the training. This finding will assist the academia by highlighting the reasons to not generalize or make assumptions on the factors influencing the effectiveness of training. The academia has to treat these factors separately based on the type of organization, country, environment and people. Another important point to be addressed while sharing this theory with students was the effectiveness of training in different industries. All the studies made so far, sampled participants from the same industry. In other words, the training effectiveness was only based on the perception of the people within the same industry. However, people from other organizations might view it differently. People in the semiconductor industry might be perceived as having an effective training program but people in the textile industry might think that these training programs were not effective. As such, the evaluation theory should be expanded by considering all angles that might affect the effectiveness of training. Therefore, there is a need for the academia to play a significant role in addressing this theory compared to the real application.

\section{Managerial implications especially to the Semiconductor Wafer Fabrication Industry}

During the study, we found some of the statements used for level 1(i.e. reaction) were not suitable or out-of-date. The training manager should update the questionnaires to reflect the current needs. Outof-date questionnaires may provide inaccurate answers to the organization. As a result, wrong corrective actions may be taken. Therefore, the researcher suggests that the training manager work with trainers to develop a few sets of pre- and post-tests so that the participants may not know in advance the questions that would be asked in their classes. Mostly it was observed that the evaluation was only conducted at levels 1 and 2, where the participants and the trainer evaluated the effectiveness of the training. Level 1 involved participants' perception about the training and Level 2 evaluated the skills and knowledge gained by the participants. These two evaluations were not sufficient enough to inform the management of the effectiveness of the training. The most important components awere the skills and knowledge application, and results (ROI) of the training. Corrective actions could be taken based on the evaluation report/result. 


\section{Implications to Government Policy}

The Malaysian government has developed action plans and policies to increase employability and to be the country of choice in the Asia Pacific region for investors to invest, by:

1. Introducing free training for fresh graduates and retrenched workers.

2. Designing local university curriculum to meet industry needs.

3. Privatizing local universities.

4. Globalizing Malaysia's higher education system.

5. Introducing a 'stimulus package' to enhance domestic growth and improve market confidence. This package ensures that a larger segment of the population will benefit from the productive expenditures of the government.

\section{Future Research}

The scope of this study focused only on the technical community within a single semiconductor wafer fabrication company. One of the possible areas for future research could be the larger and targeted industries, such as textile, banking, etc. Future research can also look at two more items in evaluating training effectiveness. The first is to evaluate training effectiveness from the perspective of others. The second is the study also showed that no evaluation was conducted on customers or suppliers to gauge their perspectives. The researchers suggest naming this evaluation as level 5 of training effectiveness evaluation by customers or suppliers, as 'acceptation'.

\section{Conclusion}

Although this study had several limitations and room for future research, the findings of this study still had its own significance. The findings could be used by any industry when considering their efforts on training. This study showed that there were some factors such as participant, trainer, training material and company that affect the reaction, learning, behavior and result (ROI). The finding was quite interesting since behavior and results (ROI) were important elements in the effectiveness of training. The findings of this study have the potential to be used as a gauge on other technical-based organizations in other countries. The result of this study exposed new findings about the factors that affect training effectiveness in the semiconductor wafer fabrication in Malaysia. 


\section{Acknowledgements}

Special thanks to the HR and the Manufacturing teams at Silterra Malaysia Sdn. Bhd. especially to Syed Sagaf, Rudy Musnandar, Zamri, Nor Asmahan and Suria Hassan who helped us in the data collection, etc.

\section{References}

Al-Eisa, A., Furayyan, M., \& Alhemoud, A. (2009). An empirical examination of the effects of self-efficacy, supervisor support and motivation to learn on transfer intention. Management Decision, 47(8), 1221-1244.

Arsaythamby, V., \& Kiew, H. B. (2012). Hubungan antara kerja berpasukan dengan kepuasan kerja ketua panitia sekolah menengah. Internal Journal of Management Studies, 19(1), 175191.

Asplund, R., \& Salverda, W. (2004). Introduction to company training and services with focus on low skills. International Journal of Manpower, 25(1), 8-16.

Barkala, M. F., Martin, A. D., \& Gutierrez, F. T. (2000). Training in retailing: A guide for improving the supply of courses. International Journal of Retail \& Distribution Management, 28(6), 243-260.

Billington, L., Neeson, R., \& Barrett, R. (2009). The effectiveness of workshops as managerial learning opportunities. Education + Training, 51(8/9), 733-746.

Boyce, A. (1996). Effective training begins with needs assessment. Occupational Health \& Safety, 65(8), 72-73.

Cannon-Bowers, J. A., Salas, E., Tannenbaum, S. I., \& Mathieu, J. E. (1995). Toward theoretically based principles of training effectiveness: A model and initial empirical investigation. Military Psychology, 7(3), 141-164.

Edulbehram J., \& Rascher, D. (1996). Training: The competitive semiconductor manufacturing human resources project. CSM Report. University Berkeley CA.

Ellis, H. C. (1965). The transfer of learning. New York: MacMillan.

Emory, C. W. (1985). Business Research Method (3rd ed.). Homewood, IL: Richard D. Trwin.

Giangreco, A., Carugati, A., \& Sebastiano, A. (2010). Are we doing the right thing? Food for thought on training evaluation and its context. Personnel Review, 39(2), 162-177. 
Harvey, J., Bolam., Gregory, D., \& Erdos, G. (2001). The effectiveness of training to change safety culture and attitude within a highly regulated environment. Personnel Review, 30(6), 615-636.

Kirkpatrick, D. (1977). Evaluating training programs, evidence vs proof. Journal of the American Society of Training and Development, 31(11), 9-12.

Kirkpatrick, D. (1979). Techniques for evaluating training programs. Training and Development Journal, 33(6), 78-92.

Kirkpatrick, D. (1994). Evaluating training programs: The four levels. San Francisco, CA: Berrett-Koehler.

Kirkpatrick, D. (1996). Great ideas revisited: Revisiting Kirkpatrick's Four-Level Model. Journal of the American Society of Training and Development, January, 54-59.

Kirkpatrick, D. (2005). Evaluating training program: The four levels (3rd ed.). Williston, US: Berrett-Koehler.

Lingham, T., Richley, B., \& Rezaria. (2006). An evaluation system for training programs: A case study using four-phase approach. Career Development International, 4, 334-351.

Mathieu, J. E., Tannenbaum, S. I., \& Salas, D. (1992). Influences of individual and situational characteristics on measures of training effectiveness. Academy of Management Journal, 35, 828847.

McGettingan, E., \& O'Neill, D. (2009). From apprentice to construction manager and beyond: Developing a talent pipeline. Education + Training, 51(3), 220-231.

Noe, A. R. (2008). Employee training and development (4th ed.). New York: McGraw-Hill.

Sadri, G., \& Snyder, P. F. (1995). Methodological issues in assessing training effectiveness. Journal of Managerial Psychology, 10(4), 30-32.

Sanlier, N., \& Karakus, S. S. (2010). Evaluation of food purchasing behaviour of consumers from supermarkets. British Food Journal, 112(2), 140-150.

Savolainen, T. (2000). How organizations promote and avoid learning: Development of positive and negative learning cycles. Journal of Workplace Learning: Employee Counselling Today, 12(5), 195-204.

Silterra Overview. (2010). Silterra Malaysia Sdn. Bhd. Retrieved from http://www.silterra. com/overview.html

Smith, A. J., \& Piper, J. A. (1990). The tailor-made training maze: A practitioner's guide to evaluation. Journal of European Industrial Training, 14(8), 2-24.

Spatz, C., \& Kardas, E. (2008). Research methods: Ideas, techniques $\mathcal{E}$ reports. Boston: McGraw-Hill. 
Tai, W. T. (2006). Effects of training framing, general self-efficacy and training motivation of trainees' training effectiveness. Personnel Review, 35(1), 51-65.

Tsai, W. C., \& Tai, W. T. (2003). Perceived importance as a mediator of the relationship between training assignment and training motivation. Personnel Review, 32(2), 151-163.

Williams, S., Graham, S., \& Baker, B. (2003). Evaluating outdoor experiential training for leadership and teambuilding. Journal of Management Development, 22(1), 45-59.

Zafir, M. M., \& Fazilah M. H. (2011). Persekitaran stesen kerja dan niat untuk berhenti. International Journal of Management Studies, 18(2), 165-184. 